\title{
Nanolayered Diamond Sintered Compact Obtained by Direct Conversion from Highly Oriented Graphite under High Pressure and High Temperature
}

\author{
Futoshi Isobe, ${ }^{1}$ Hiroaki Ohfuji, ${ }^{1}$ Hitoshi Sumiya, ${ }^{2}$ and Tetsuo Irifune ${ }^{1}$ \\ ${ }^{1}$ Geodynamics Research Center, Ehime University, 2-5 Bunkyo-cho, Matsuyama Ehime 790-8577, Japan \\ ${ }^{2}$ Electronics \& Materials R\&D Laboratories, Sumitomo Electric Industries, LTD., 1-1-1, Koya-kita, Itami, Hyogo 664-0016, Japan \\ Correspondence should be addressed to Futoshi Isobe; f-isobe@mserv.sci.ehime-u.ac.jp
}

Received 25 January 2013; Revised 19 March 2013; Accepted 19 March 2013

Academic Editor: Jun Liu

Copyright ( $\odot 2013$ Futoshi Isobe et al. This is an open access article distributed under the Creative Commons Attribution License, which permits unrestricted use, distribution, and reproduction in any medium, provided the original work is properly cited.

A new type of polycrystalline sintered diamond has been successfully synthesized by direct conversion from highly oriented pyrolytic graphite at $15 \mathrm{GPa}$ and $2300^{\circ} \mathrm{C}$. It is optically transparent and consists entirely of layered nanocrystals (50-100 nm thick) of cubic diamond, which are tightly bound to each other and have strong [111] preferred orientation along the stacking direction. This nanolayered diamond has excellent indentation hardness ( 114 GPa in Knoop scale) comparable to the highest values obtained from single crystalline diamond. Furthermore, it is expected to have significantly high wear resistance on both ends of cylindrical sintered compact, since the surfaces are terminated exclusively by the hardest $\{111\}$ planes of the layered diamond nanocrystals.

\section{Introduction}

Since a major breakthrough was made in the synthesis of pure binderless nanopolycrystalline diamond (NPD) from graphite [1], an extensive series of studies have been conducted on its conversion mechanism, microtextures, and physical properties. The optical transparency and ultra-high hardness (surpassing that of single crystalline diamond [2]) of NPD have drawn considerable attention for various industrial uses such as for cutting and wear-resistant tools [3] and scientific applications such as for anvils for high pressure apparatuses [4-6].

NPD is characterized to have a unique microtexture usually composed of a mixture of randomly oriented equigranular crystals of a few to several tens of nanometers and lamellar crystals stacked along [111] direction of diamond [7]. The origin of such two types of microtextures of NPD is derived from the heterogeneous crystalline features of the starting graphite source (polycrystalline graphite compact), where relatively large, well-crystallized graphite flakes (cokederived) are mixed in a nanocrystalline graphite matrix (binder-pitch-derived) [8]. The former graphite crystals transform to diamond by the diffusion-limited (Martensitic) process via metastable hexagonal diamond as an intermediate phase, maintaining the original layered structure (forming lamellas), while the latter matrix converts to granular diamond nanocrystals by the diffusion process in which nucleation and subsequent grain growth of diamond (cubic) take place by atomic diffusion [8-10]. Therefore, the transformation pathway and resulting microtexture of diamond produced through direct conversion by high pressure and high temperature (HPHT) method is most likely determined by the crystallinity (crystallite size) of the initial graphite sources. In fact, when nongraphitic or poorly crystalline carbon sources (such as finely milled graphite, glassy carbon, fullerene, etc.) are used as the starting material, the transformation proceeds exclusively by the diffusion process, producing NPD composed only of granular nanocrystals without lamellar crystals and the hexagonal diamond intermediate $[9$, 11]. In contrast, when using well-crystalline highly oriented graphite, a layered material composed of a mixture of cubic and hexagonal diamonds, which are in a coaxial relation c-dia ${ }^{*}[111] / / \mathrm{h}$-dia ${ }^{*}[100]$ along the stacking direction, is obtained [9]. However, the latter aspect has not been investigated systematically using a large-volume press, and it is therefore of interest to study the effect of synthetic 
conditions on the microtexture and phases produced as well as the physical property of such products.

In this study, we have synthesized a new binderless sintered diamond which is optically transparent and consists entirely of layered (highly oriented) nanocrystals of cubic diamond by direct conversion from highly oriented graphite. Since the top (and bottom) surface of this layered diamond is occupied exclusively by (111) faces possessing an extremely high abrasion resistance, it can potentially be applied for novel wear-resistance tools.

\section{Experimental}

2.1. Characterization of Starting Materials. The starting material used in the present study is highly oriented pyrolytic graphite (HOPG) obtained by pyrolytic decomposition of hydrocarbon gas and subsequent annealing of the deposit under pressure. Raman spectra obtained from the sample using an Ar ion laser $(\lambda=514.5 \mathrm{~nm})$ was characterized by the intense $\mathrm{E} 2 \mathrm{~g}$ stretching mode centered at $1580 \mathrm{~cm}^{-1}$, while defect originated, so-called D band (centered at $1350 \mathrm{~cm}^{-1}$ ) was not observed at all, indicating high crystalline state of the sample. We further examined the HOPG sample by transmission electron microscopy (TEM; JEOL, JEM-2010) to directly observe the crystallite size and degree of preferred orientation. A focused ion beam (FIB) system (JEOL, JEM9310FIB) was used to cut out a thin cross-section (ca. 10 $\times 10 \times 0.1 \mu \mathrm{m}$ ) in parallel to the stacking direction (i.e., $c$ axis) for TEM observation. Figure 1 shows a typical TEM image of HOPG used in the present study. It is clear from the diffraction contrast that individual graphite layers are of 20-200 $\mathrm{nm}$ thick (along $c$-axis direction), but have far longer periodicity (larger crystallite size) up to several micrometer in the lateral direction (along a-b plane). The corresponding selected area electron diffraction (SAED) pattern (Figure 1 inset) indicates that each layer is highly oriented toward [002] direction of graphite with misorientation of much less than a few degrees. The fact that both $10 \mathrm{l}$ and $11 \mathrm{l}$ spots appear in one SAED suggests the presence of relatively large misorientation (rotation) along the stacking direction (caxis), which can also be recognized as the varying degrees of diffraction contrasts shown by the individual stacked layers.

\subsection{High Pressure and High Temperature Experiment. High} pressure and high temperature experiments were conducted using a 3000 ton Kawai-type multianvil apparatus (ORANGE-3000 at Ehime University). We used $36 \mathrm{~mm}$ tungsten carbide anvils with a truncated edge length (TEL) of $5 \mathrm{~mm}$ and a cell assembly which is simply scaled down from that used in our previous study [12]. Experiments were performed at a fixed pressure of $15 \mathrm{GPa}$ and at various temperatures ranging $1000-2300^{\circ} \mathrm{C}$. Pressures were estimated from a pressure-load calibration curve that was obtained based on the phase transition of pressure standard materials (ZeTe, $12 \mathrm{GPa} ; \mathrm{ZnS}, 15.6 \mathrm{GPa}$ ) at room temperature. Pressures at high temperatures (during heating) were expected to be lower by $1-1.5 \mathrm{GPa}$ than those at room temperature due to plastic flow of the high pressure cell assembly, according to our empirical observation [13]. Temperature was estimated from

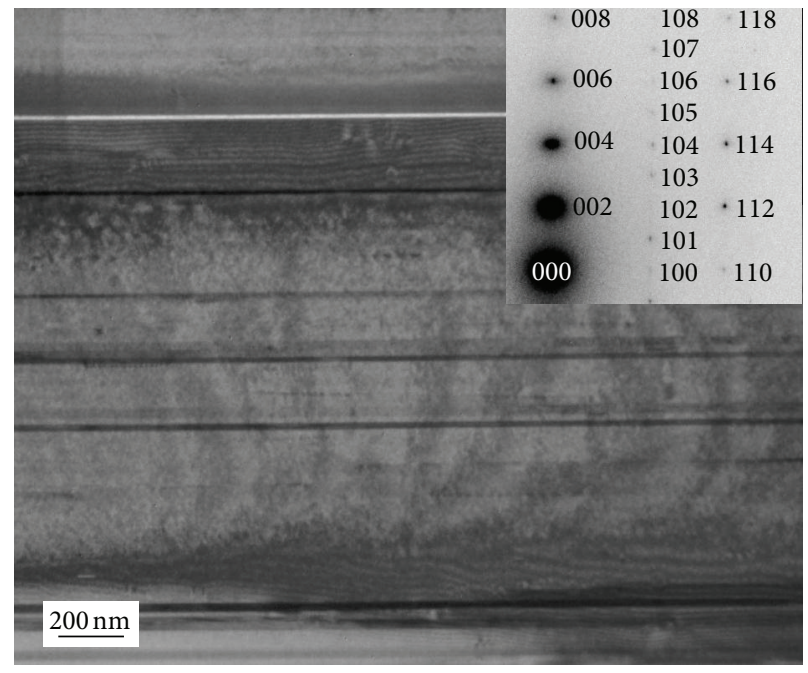

FIGURE 1: A bright field TEM image of HOPG starting material and the corresponding SAED pattern. It consists of layered crystals of $\sim 20-200 \mathrm{~nm}$ thick which show a strong [002] preferred orientation along the stacking direction. The orientation along the lateral direction is not uniform and varies layer by layer, as indicated by diffraction contrast.

the relationship between input electrical power and generated temperature obtained in a separate run using the identical cell assembly. In the temperature calibration run, temperature was measured up to $2400^{\circ} \mathrm{C}$ using a $\mathrm{W}_{97} \mathrm{Re}_{3}-\mathrm{W}_{75} \mathrm{Re}_{25}$ thermocouple, which was located at the center of the sample chamber. The systematic error in temperature estimation is empirically in the order of $\pm 50-100^{\circ} \mathrm{C}$. The sample was compressed to a target pressure, then heated to a target temperature for $20 \mathrm{~min}$ and decompressed within a few hours.

Recovered products were treated with hydrofluoric-nitric acid to remove the surrounding metal capsule. They were firstly examined by a focused X-ray diffractometer (Rigaku RAPID II-V) with $\mathrm{Cu} K \alpha$ radiation $(\lambda=1.5419)$ operated at $40 \mathrm{kV}$ and $30 \mathrm{~mA}$ and Raman spectroscopy (Renishaw RSSYS 1000) equipped with $\mathrm{Ar}^{+}$laser for phase identification. Each product was then processed by FIB system to prepare thin foil sections for microstructure observation using TEM.

\section{Result and Discussion}

Experimental conditions and phases identified in the recovered products are summarized in Table 1 . The sample synthesized at $1000-1800^{\circ} \mathrm{C}$ are black and opaque, while that at $2300^{\circ} \mathrm{C}$ shows brownish yellow color and optical transparency like NPD synthesized from polycrystalline graphite [14], as shown in Figures 2(a) and 2(b), respectively. Figure 3 shows $\mathrm{X}$-ray diffraction patterns of the samples recovered from $1000^{\circ} \mathrm{C}, 1300^{\circ} \mathrm{C}, 1800^{\circ} \mathrm{C}$, and $2300^{\circ} \mathrm{C}$ at $15 \mathrm{GPa}$. The formation of cubic and hexagonal diamonds is observed even in the sample from the lowest temperature, although a considerable amount of graphite starting material still remains unreacted as indicated by the intense 002 (basal plane) diffraction peak. With increase in heating temperature, 


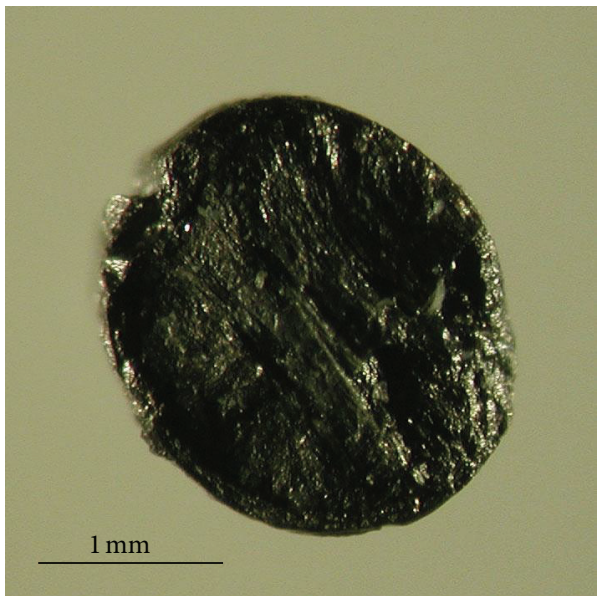

(a)

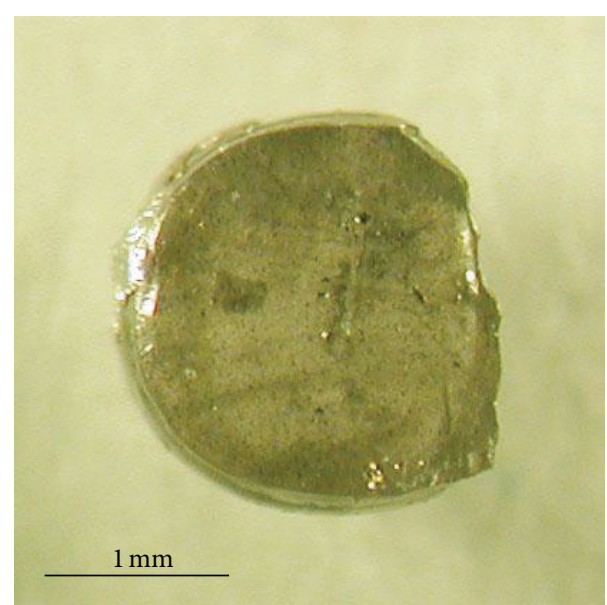

(b)

FIGURE 2: Optical micrograph images of recovered samples synthesized at $15 \mathrm{GPa}$ and $1800^{\circ} \mathrm{C}$ (a) and $15 \mathrm{GPa}$ and $2300^{\circ} \mathrm{C}(\mathrm{b})$.

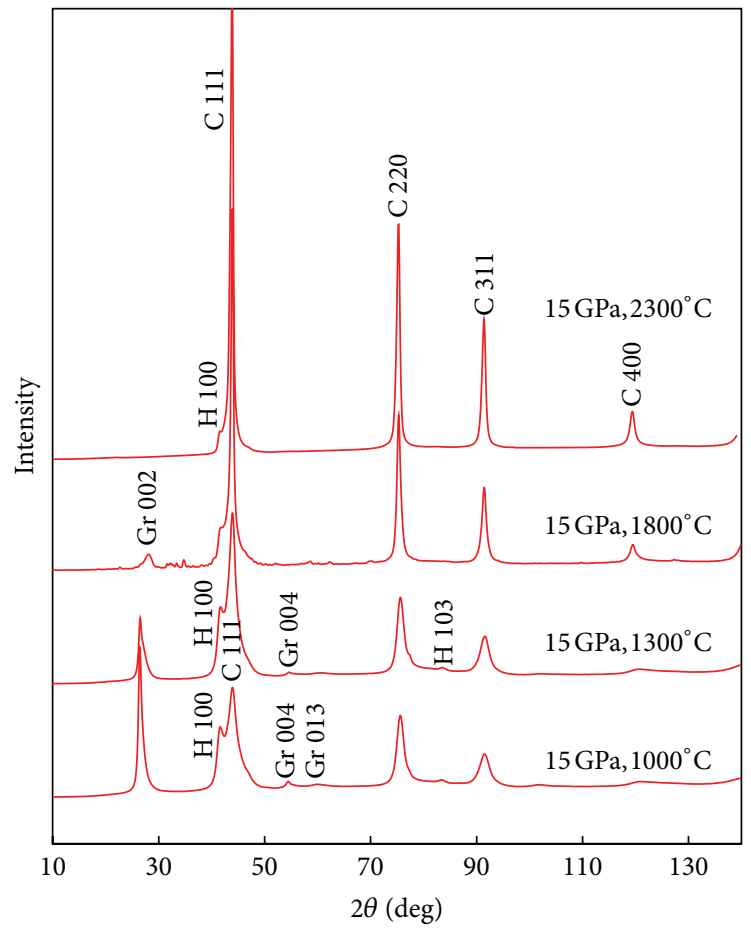

FIgURE 3: X-ray diffraction patterns of recovered samples treated at $15 \mathrm{GPa}$ and $1000^{\circ} \mathrm{C}, 1300^{\circ} \mathrm{C}, 1800^{\circ} \mathrm{C}$, and $2300^{\circ} \mathrm{C}$. $\mathrm{Gr}=$ Graphite, $\mathrm{H}=$ hexagonal diamond, $\mathrm{C}=$ cubic diamond.

the cubic diamond peaks become stronger and sharper, while the graphite 002 peak decreases and eventually disappears above $1800^{\circ} \mathrm{C}$. The hexagonal diamond 100 peak also gradually decreases with increase in temperature, although it does not completely vanish even at $2300^{\circ} \mathrm{C}$. It should be noted that the observed lower limit temperature (below $1000^{\circ} \mathrm{C}$ ) for cubic diamond formation from highly oriented graphite is remarkably lower than that $\left(1500-1600^{\circ} \mathrm{C}\right)$ required for the conversion from polycrystalline graphite and other nongraphitic carbon sources [11]. This is likely due to
TABLE 1: Synthesis conditions and experimental results.

\begin{tabular}{lcccc}
\hline$P(\mathrm{GPa})$ & $T\left({ }^{\circ} \mathrm{C}\right)$ & $t(\mathrm{~min})$ & Phases & Optical appearance \\
\hline 15 & 2300 & 20 & C-dia, H-dia* & Transparent \\
15 & 1800 & 20 & Gr, H-dia, C-dia & Opaque \\
15 & 1300 & 20 & Gr, H-dia, C-dia & Opaque \\
15 & 1000 & 20 & Gr, H-dia, C-dia & Opaque \\
\hline
\end{tabular}

Gr: graphite, H-dia: Hexagonal diamond, C-dia: cubic diamond, ${ }^{*}$ : trace amount.

the difference in transformation mechanism from different graphite sources. Martensitic transformation is found to be responsible for the diamond formation from highly oriented graphite as will be described later, while diffusion-controlled process is the dominant mechanism for the formation from polycrystalline graphite having much lower crystallinity. Since the former process does not require the long-range diffusion of atoms, it generally has lower activation energy for the transformation to proceed at lower temperature.

Figures 4(a), 4(b), and 4(c) show TEM images and corresponding SAED pattern of samples synthesized at $1000^{\circ} \mathrm{C}$, $1800^{\circ} \mathrm{C}$, and $2300^{\circ} \mathrm{C}$ at $15 \mathrm{GPa}$, respectively. All the products including that from $1300^{\circ} \mathrm{C}$ (not shown) consist exclusively of layered textures, which develop parallel to the original stacking of the starting HOPG (Figure 1). SAED analysis reveals that the samples heated at $1000^{\circ} \mathrm{C}$ and $1800^{\circ} \mathrm{C}$ consist of a mixture of graphite $(\mathrm{Gr})$, hexagonal diamond $(\mathrm{H}-$ dia), and cubic diamond (C-dia) which are all arranged in coaxial relationships: Gr [002] $]^{*} / / \mathrm{H}-\mathrm{dia}[100]^{*} / / \mathrm{C}-\mathrm{dia}[111]^{*}$ along the stacking direction. Such microtexture and coaxial relations indicate that the phase transition from graphite to cubic diamond via hexagonal diamond intermediate occurred essentially by martensite-like mechanism at the studied $P T$ conditions. This is because if the phase transition occur by nucleation and growth mechanism, both the original layered texture of graphite starting material and lattice relations among the three phases would not be preserved, like the case of nanopolycrystalline diamond which consists 


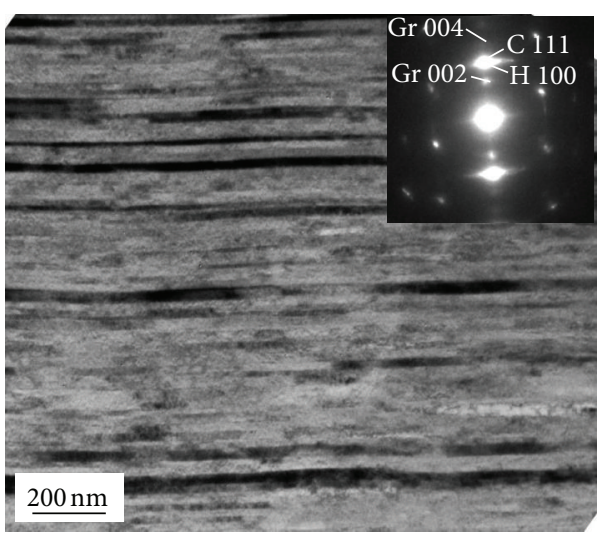

(a)

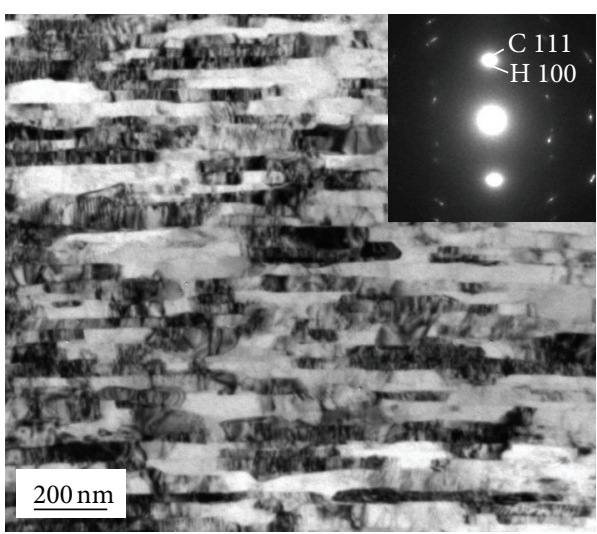

(c)

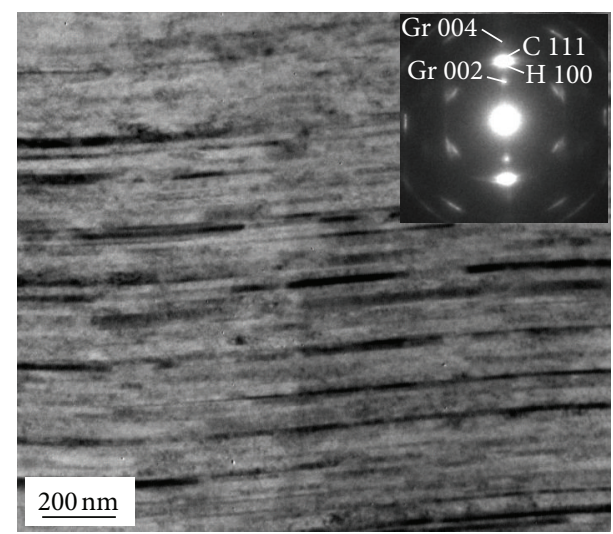

(b)

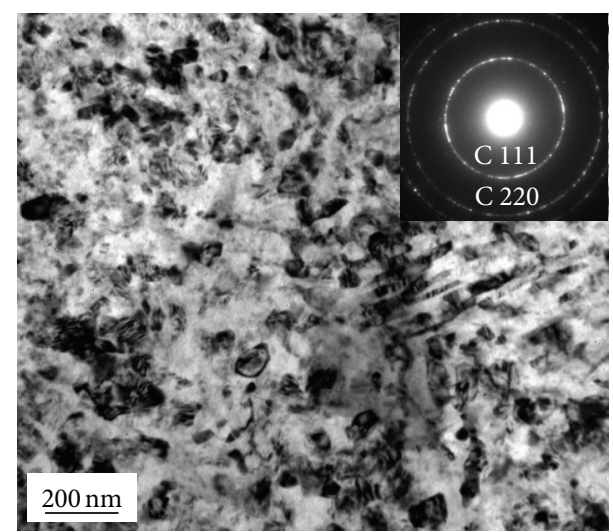

(d)

FIGURE 4: TEM images and ED patterns of recovered samples treated at $15 \mathrm{GPa}$ and $1000^{\circ} \mathrm{C}(\mathrm{a})$, at $15 \mathrm{GPa}$ and $1800^{\circ} \mathrm{C}(\mathrm{b})$, and $15 \mathrm{GPa}$ and $2300^{\circ} \mathrm{C}$ (c). A TEM image of nanopolycrystalline diamond synthesized from polycrystalline graphite at the same $\mathrm{P}$, T condition is also shown in (d) as a comparison.

mostly of randomly oriented granular crystals $[7-9,11]$. The martensite-like transformation of graphite to hexagonal diamond and cubic diamond is thought to occur by the sliding and/or buckling of graphite planes (e.g., $[15,16])$ and predominantly takes place when well-crystalline graphite is used as a starting material $[8,9]$. The sample synthesized at $15 \mathrm{GPa}$ and $2300^{\circ} \mathrm{C}$ consists mostly of cubic diamond and of a small amount of hexagonal diamond, which are also in the coaxial relation stated above, suggesting that the conversion of graphite to diamonds fully completes above $1800^{\circ} \mathrm{C}$ at this pressure. Judging from the diffraction contrast in the TEM images, the thickness of individual layers is $<5-30 \mathrm{~nm}$ in the samples synthesized at $1000-1800^{\circ} \mathrm{C}$, while it is apparently thicker $(50-100 \mathrm{~nm})$ in that at $2300^{\circ} \mathrm{C}$, which indicates that the grain growth of layered cubic diamond is accelerated by atomic diffusion at higher temperature.

A well-sintered body of layered diamond synthesized at $15 \mathrm{GPa}$ and $2300^{\circ} \mathrm{C}$ was subjected to the Knoop indentation test to evaluate its hardness. Details of the indentation procedure are described in the previous study [2]. Since the sample was expected to have mechanical anisotropy due to its layered texture, the indentation tests were performed both on the top surface and on the lateral cross-section of the cylindrical

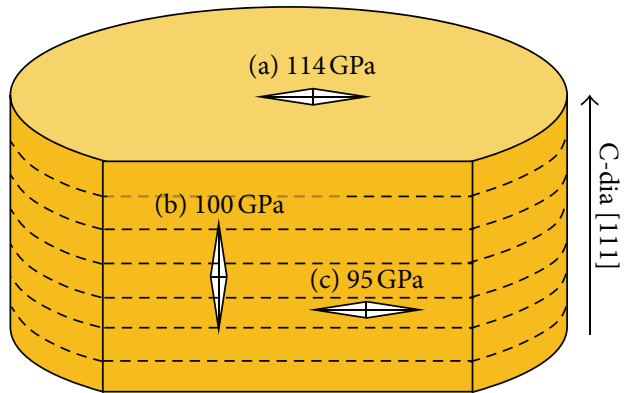

FIGURE 5: Schematic illustration of the processed nanolayered diamond sintered body for Knoop indentation test. The relationship between the diagonal of the Knoop indenter and measurement positions are shown.

sample (Figure 5) after mechanical polishing using a metalbonded diamond wheel. Hardness values yielded at each indent position (average from three median values out of five) are also shown in the figure. Knoop hardness on the top surface is $114 \mathrm{GPa}$, while those on the lateral surface are slightly lower $(\sim 100 \mathrm{GPa})$. These values are comparable to that of the hardest plane direction $((111)\langle 11-2\rangle)$ of synthetic 
type Ib single crystal diamond but are somewhat lower than that of nanopolycrystalline diamond ( 120-145 GPa) synthesized from polycrystalline graphite [2]. This is probably attributed to the difference in microtexture between the present nanolayered diamond and NPD. The grain size of the individual layered crystal in the former is much larger in the lateral direction than the average grain size $(<50-100 \mathrm{~nm})$ of the latter. Assuming the fracture toughening mechanism of polycrystalline diamond follows the Hall-Petch law [17], the indentation strength decreases with increasing grain size above a certain critical grain size. The lower hardness values on the lateral surface are likely a result of the orientation effect: since the layered diamond nanocrystals orient their [111] along the stacking direction (parallel to the top surface), the indentations onto the lateral surface promotes the dominant slip deformation along (111) $\langle 110\rangle$ of layered crystals. Nevertheless, the observed high hardness equivalent to that of single crystalline diamond suggests that individual layered nanocrystals are strongly bound to each other, and the influence of cleavage on the indentation strength appears to be negligible.

The unique microtexture and high indentation hardness of the new polycrystalline diamond synthesized in this study offer a potential application for wear-resistant tools. The antiwear property of cubic diamond is highly anisotropic depending on it crystallographic orientation, and the $\{111\}$ planes provide the highest wear resistance based on mechanical abrasion test [18]. The cutting tools made of single crystalline diamonds are usually designed by taking into account the anisotropic abrasion property. Recent study by Sumiya and Harano [3] showed that NPD synthesized from polycrystalline graphite has remarkably antiwear property; its mechanical wear rate evaluated using a high-speed polishing machine is as small as that of a high wear-resistance direction, (112) $\langle 110\rangle$ of single crystalline diamond. They suggested that the high wear resistance of NPD is attributed to the extremely strong binding nature of the constituent nanocrystals and the presence of a number of grains with $\{111\}$ planes facing to the surface. Indeed, a careful abrasion test conducted using CVDgrown micropolycrystalline diamond by El-dasher et al., [19] demonstrated super wear resistance of $\{111\}$ planes. Since our new nanolayered diamond has top surfaces which are terminated exclusively by $\{111\}$ due to the strong preferred orientation of individual crystals, it is expected to provide significantly higher antiwear performance.

\section{Conclusion}

We have synthesized a new type of nanopolycrystalline diamond by direct conversion from highly oriented pyrolitic graphite using a multianvil press at $15 \mathrm{GPa}, 1000-2300^{\circ} \mathrm{C}$. It consists purely of layered nanocrystals of cubic diamond (50$100 \mathrm{~nm}$ thick), which are strongly bound to each other and create strong [111] preferred orientation along the stacking direction. The unique microtexture is formed as a result of martensitic transformation from graphite probably via metastable hexagonal diamond as an intermediate, where original layered structure of the starting material and crystal lattice relations among them are maintained. The present nanolayered diamond has excellent indentation hardness ( $114 \mathrm{GPa}$ in Knoop scale) comparable to the highest values obtained from single crystalline diamond. Moreover, since the top surface of the cylindrical sintered compact is terminated exclusively by the hardest $\{111\}$ planes, it is expected to possess a remarkably high wear-resistance property.

\section{Acknowledgments}

This work was supported by Global COE program of Ehime University "Center for Advanced Experimental and Theoretical Deep Earth Mineralogy" and also partly by Grant-inAid for Young Scientists (B) (no. 20740255, representative: H. Ohfuji) from Ministry of Education, Science and Culture, Japan. F. Isobe was supported by a JSPS Research Fellowship for Young Scientists. The authors thank T. Shinmei of Ehime University for his technical support.

\section{References}

[1] T. Irifune, A. Kurio, S. Sakamoto, T. Inoue, and H. Sumiya, "Materials: ultrahard polycrystalline diamond from graphite," Nature, vol. 421, no. 6923, pp. 599-600, 2003.

[2] H. Sumiya and T. Irifune, "Indentation hardness of nano-polycrystalline diamond prepared from graphite by direct conversion," Diamond and Related Materials, vol. 13, no. 10, pp. 17711776, 2004.

[3] H. Sumiya and K. Harano, "Distinctive mechanical properties of nano-polycrystalline diamond synthesized by direct conversion sintering under HPHT,' Diamond and Related Materials, vol. 24, pp. 44-48, 2012.

[4] Y. Nakamoto, M. Sakata, H. Sumiya et al., "High-pressure generation using nano-polycrystalline diamonds as anvil materials," Review of Scientific Instruments, vol. 82, no. 6, Article ID 066104, 2011.

[5] T. Kunimoto and T. Irifune, "Pressure generation to $125 \mathrm{GPa}$ using a 6-8-2 type multianvil apparatus with no-polycrystalline diamond anvils," Journal of Physics, vol. 215, no. 1, Article ID 012190, 2010

[6] H. Ohfuji, T. Okada, T. Yagi, H. Sumiya, and T. Irifune, "Application of nano-polycrystalline diamond to laser-heated diamond anvil cell experiments," High Pressure Research, vol. 30, no. 1, pp. 142-150, 2010.

[7] H. Sumiya, T. Irifune, A. Kurio, S. Sakamoto, and T. Inoue, "Microstructure features of polycrystalline diamond synthesized directly from graphite under static high pressure," Journal of Materials Science, vol. 39, no. 2, pp. 445-450, 2004.

[8] H. Ohfuji, S. Okimoto, T. Kunimoto et al., "Influence of graphite crystallinity on the microtexture of nano-polycrystalline diamond obtained by direct conversion," Physics and Chemistry of Minerals, vol. 39, pp. 543-552, 2012.

[9] H. Ohfuji and K. Kuroki, "Origin of unique microstructures in nano-polycrystalline diamond synthesized by direct conversion of graphite at static high pressure," Journal of Mineralogical and Petrological Sciences, vol. 104, no. 5, pp. 307-312, 2009.

[10] C. L. Guillou, F. Brunet, T. Irifune, H. Ohfuji, and J. N. Rouzaud, "Nanodiamond nucleation below $2273 \mathrm{~K}$ at $15 \mathrm{GPa}$ from carbons with different structural organizations," Carbon, vol. 45, no. 3, pp. 636-648, 2007.

[11] H. Sumiya, H. Yusa, T. Inoue, H. Ofuji, and T. Irifune, "Conditions and mechanism of formation of nano-polycrystalline 
diamonds on direct transformation from graphite and nongraphitic carbon at high pressure and temperature," High Pressure Research, vol. 26, no. 2, pp. 63-69, 2006.

[12] F. Isobe, T. Irifune, T. Shinmei, S. Suga, N. Nishiyama, and H. Sumiya, "Lowering P, T boundary for synthesis of pure nanopolycrystalline diamond," Journal of Physics, vol. 215, no. 1, Article ID 012136, 2010.

[13] T. Irifune, A. Kurio, S. Sakamoto, T. Inoue, H. Sumiya, and K. I. Funakoshi, "Formation of pure polycrystalline diamond by direct conversion of graphite at high pressure and high temperature," Physics of the Earth and Planetary Interiors, vol. 143-144, no. 1-2, pp. 593-600, 2004.

[14] H. Sumiya, K. Harano, K. Arimoto, H. Kagi, S. Odake, and T. Irifune, "Optical characteristics of nano-polycrystalline diamond synthesized directly from graphite under high pressure and high temperature," Japanese Journal of Applied Physics, vol. 48, no. 12, Article ID 120206, 2009.

[15] F. P. Bundy and J. S. Kasper, "Hexagonal diamond-a new form of carbon," The Journal of Chemical Physics, vol. 46, no. 9, pp. 3437-3446, 1967.

[16] S. Scandolo, M. Bernasconi, G. L. Chiarotti, P. Focher, and E. Tosatti, "Pressure-induced transformation path of graphite to diamond," Physical Review Letters, vol. 74, no. 20, pp. 4015-4018, 1995.

[17] S. Yip, “The strongest size," Nature, vol. 391, no. 6667, pp. 532533, 1998.

[18] E. M. Wilks and J. Wilks, "The resistance of diamond to abrasion,” Journal of Physics D, vol. 5, no. 10, pp. 1902-1919, 1972.

[19] B. S. El-Dasher, J. J. Gray, J. W. Tringe et al., "Crystallographic anisotropy of wear on a polycrystalline diamond surface," Applied Physics Letters, vol. 88, no. 24, Article ID 241915, 3 pages, 2006. 

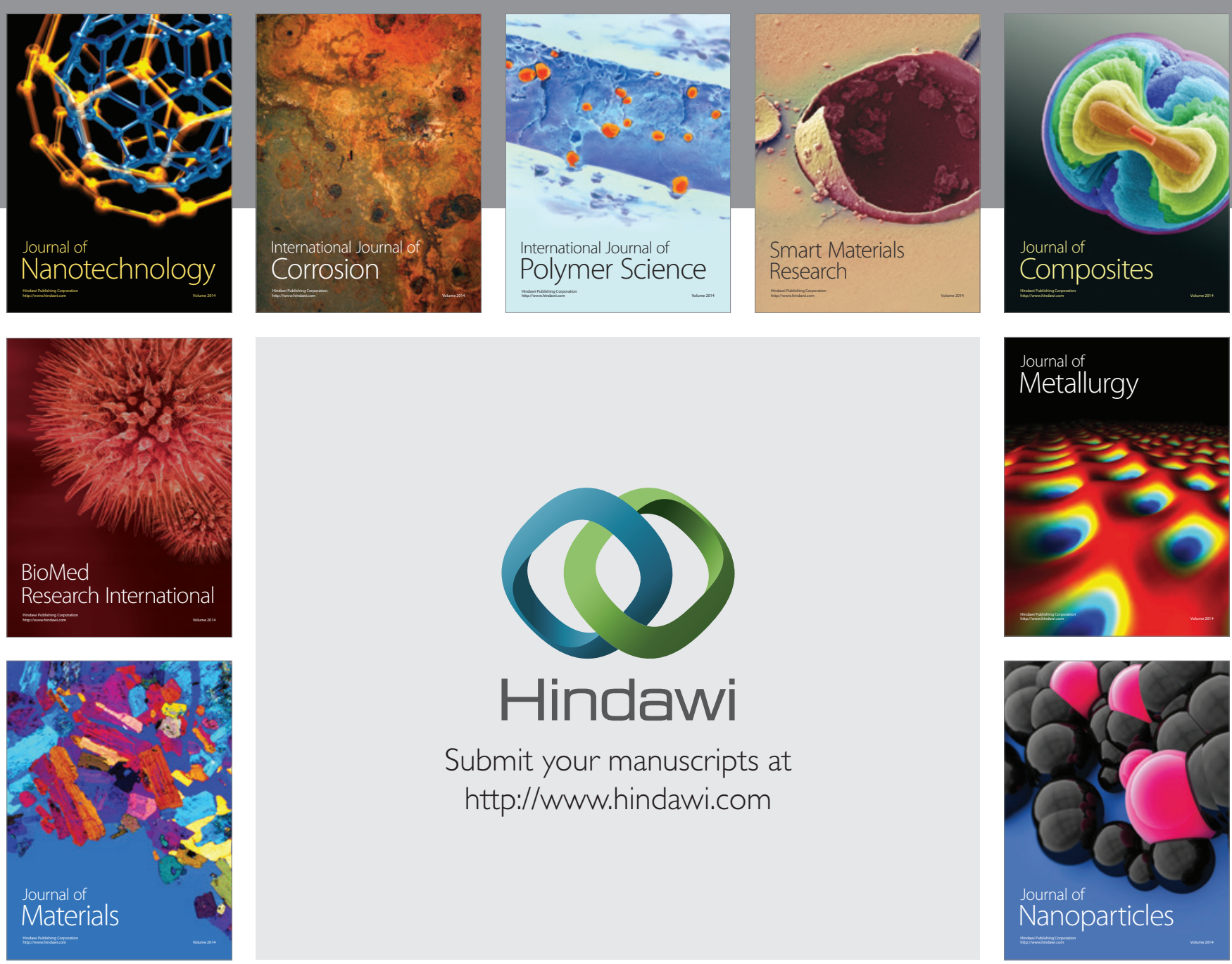

Submit your manuscripts at http://www.hindawi.com
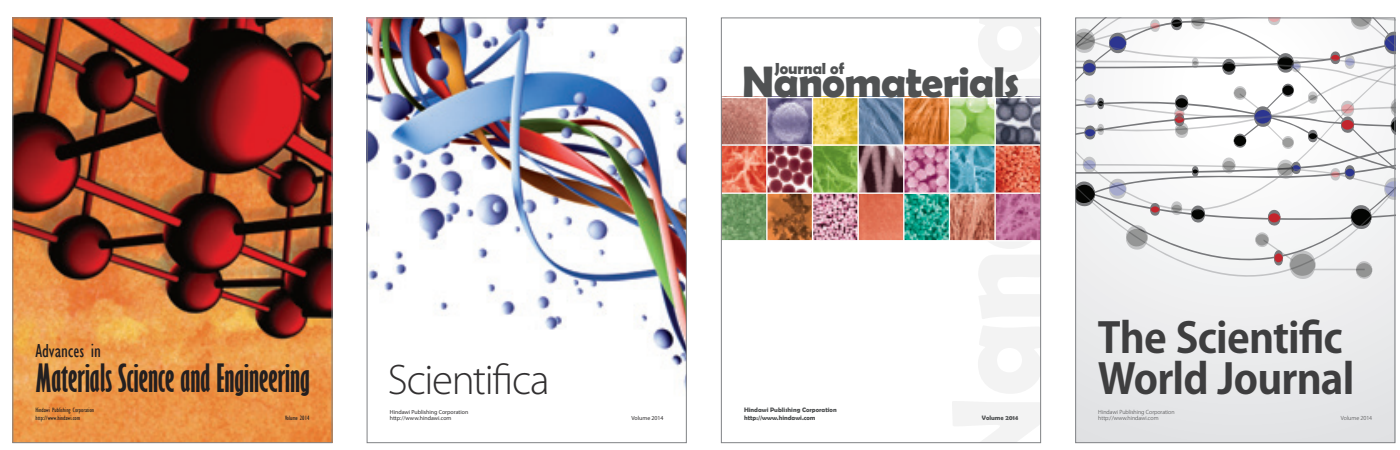

\section{The Scientific World Journal}
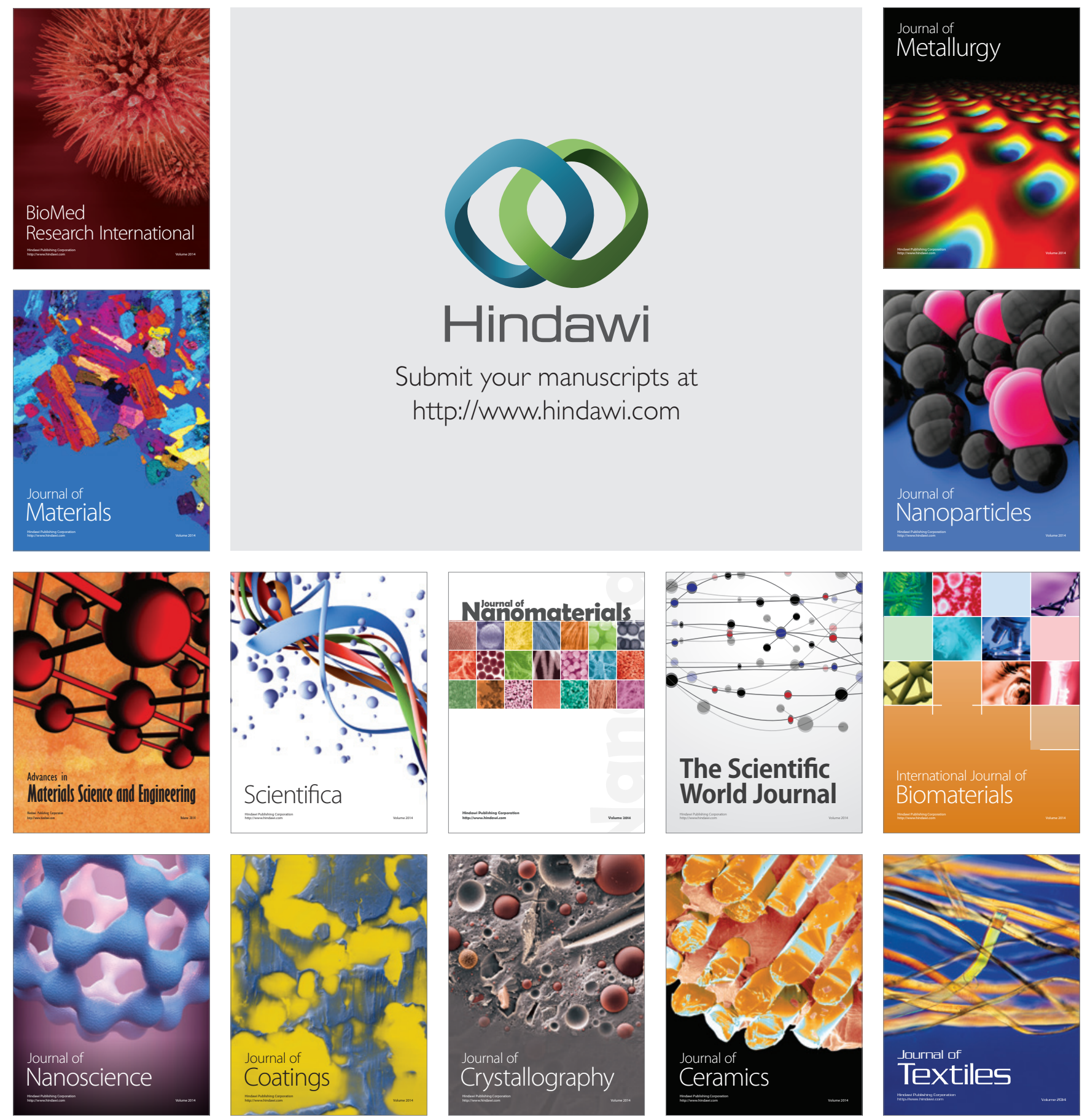